ing the excitation of chlorophyll via the Soret band, using a blue laser (e.g., 407 $\mathrm{nm})$. Similar excitation in combination with the use of specific band-pass filters (420-440 $\mathrm{nm}$ and 460-490 nm) could be used to differentiate between chlorophyll $a$ and chlorophyll $b$, respectively. Such conditions are suitable for isolating mutants of algal species containing both chlorophyll $a$ and $b$ or for the examination of protoplasts of higher plants. Finally, mutants of organisms in which carotenoids serve as the major light-harvesting pigments could also be isolated; for example, the level of fucoxanthine, the predominant carotenoid in certain algae, is reflected in a broad fluorescence band centered around $530 \mathrm{~nm}$.

In summary, the four genes isolated thus far and further characterization of their products (11-15) provided some clues to the mechanism of degradation of the phycobilisome, the highly abundant macromolecular structure comprising the cyanobacterial lightharvesting complex. The isolation of novel nonbleaching mutants, however, seems to be a rate-limiting step in the study of the degradation process and its regulation. FACS-mediated selection of nonbleaching mutants will undoubtedly lead to a better understanding of the molecular mechanisms underlying the modulation of light harvesting in response to environmental cues by facilitating the isolation of novel mutants.

\section{ACKNOWLEDGMENTS}

This work was supported by United States-Israel Binational Science Foundation (grant no. 9800146 to R.S. and A.R. Grossman) and by The Israel Science Foundation (grant no. 210/99 to R.S.).

\section{REFERENCES}

1.Foyer, C.H. and G. Noctor. 2000. Oxygen processing in photosynthesis: regulation and signaling. New Phytol. 146:359-388.

2.Niyogi, K.K. 1999. Photoprotection revisited: genetic and molecular approaches. Annu. Rev. Plant Physiol. Plant Mol. Biol. 50:333-359.

3.MacColl, R. 1998. Cyanobacterial phycobilisomes. J. Struct. Biol. 124:311-334.

4.Collier, J.L. and A.R. Grossman. 1994. A small polypeptide triggers complete degra- dation of light-harvesting phycobiliproteins in nutrient-deprived cyanobacteria. EMBO J. 13:1039-1047.

5.Dolganov, N. and A.R. Grossman. 1999. A polypeptide with similarity to phycocyanin alpha-subunit phycocyanobilin lyase involved in degradation of phycobilisomes. J. Bacteriol. 181:610-617.

6.Schwarz, R. and A.R. Grossman. 1998. A response regulator of cyanobacteria integrates diverse environmental signals and is critical for survival under extreme conditions. Proc. Natl. Acad. Sci. USA 95:11008-11013.

7.van Waasbergen, L.G., N. Dolganov, and A.R. Grossman. 2002. $n b l \mathrm{~S}$, a gene involved in controlling photosynthesis-related gene expression during high light and nutrient stress in Synechococcus elongatus PCC 7942. J. Bacteriol. 184:2481-2490.

8.Grossman, A.R., D. Bhaya, and Q.F. He. 2001. Tracking the light environment by cyanobacteria and the dynamic nature of light harvesting. J. Biol. Chem. 276:11449-11452.

9.Bhaya, D., A. Takahashi, P. Shahi, and A.R. Grossman. 2001. Novel motility mutants of Synechocystis strain PCC 6803 generated by in vitro transposon mutagenesis. J. Bacteriol. 183:6140-6143.

10.Phinney, D.A. and T.L. Cucci. 1989. Flow cytometry and phytoplankton. Cytometry 10:511-521.

11.Richaud, C., G. Zabulon, A. Joder, and J.C. Thomas. 2001. Nitrogen or sulfur starvation differentially affects phycobilisome degradation and expression of the $n b l \mathrm{~A}$ gene in Synechocystis strain PCC 6803. J. Bacteriol. 183:2989-2994.
12.Sauer, J., M. Gorl, and K. Forchhammer. 1999. Nitrogen starvation in synechococcus PCC 7942: involvement of glutamine synthetase and NtcA in phycobiliprotein degradation and survival. Arch. Microbiol. 172:247-255.

13.Strauss, H., R. Misselwitz, D. Labudde, $\mathbf{S}$. Nicklisch, and K. Baier. 2002. NblA from Anabaena sp. PCC 7120 is a mostly alpha-helical protein undergoing reversible trimerization in solution. Eur. J. Biochem. 269:46174624.

14.Luque, I., G. Zabulon, A. Contreras, and J. Houmard. 2001. Convergence of two global transcriptional regulators on nitrogen induction of the stress-acclimation gene $n b l \mathrm{~A}$ in the cyanobacterium Synechococcus sp. PCC 7942. Mol. Microbiol. 41:937-947.

15.Luque, I., J.A. Ochoa De Alda, C. Richaud, G. Zabulon, J.C. Thomas, and J. Houmard. 2003. The NblAI protein from the filamentous cyanobacterium Tolypothrix PCC 7601: regulation of its expression and interactions with phycobilisome components. Mol. Microbiol. 50:1043-1054.

Received 3 February 2004; accepted 15 March 2004.

Address correspondence to Rakefet Schwarz, Faculty of Life Sciences, BarIlan University, 52900 Ramat-Gan, Israel. e-mail:schwarr2@mail.biu.ac.il

\title{
Rapid analysis of oxysterols by HPLC and UV spectroscopy
}

\author{
Ignacio R. Rodriguez \\ National Eye Institute, National Institutes of Health, Bethesda, MD, USA
}

BioTechniques 36:952-958 (June 2004)

Oxidized derivatives of cholesterol are an important group of molecules with potent pharmacological properties (1) that have been implicated in atherosclerosis and other age-related diseases (2). The accurate identification and quantification of oxysterols is complicated by numerous factors, including low sensitivity of detection, interference by other compounds, tedious analytical methods, and instability during alkaline hydrolysis.
Cholesterol and most oxysterols have ultraviolet (UV) absorption maximums below $200 \mathrm{~nm}$ and are extremely hydrophobic. This creates a unique chromatography problem because most solvents capable of solubilizing oxysterols (with dielectric constants below 30) absorb light strongly between 190 and $200 \mathrm{~nm}$ and their use reduces the sensitivity of detection by UV absorption. Water and acetonitrile have low UV absorption profiles above 
$190 \mathrm{~nm}$ but are poor solvents for oxysterols with dielectric constants of 80 and 36 , respectively. A recently published high-performance liquid chromatography (HPLC) technique (3) can separate most oxysterols, but it is complex to perform and uses solvents with strong UV absorption, which reduces the sensitivity of detection.

This protocol resolved the poor solubility problems by using high concentrations of acetonitrile at high temperatures. However, this alone did not resolve the chromatography problems because most commercially available C-18 columns still retained cholesterol and oxysterols, requiring stronger solvents with high UV absorption below $200 \mathrm{~nm}$ (methanol) or long elution times that broadened the peaks and reduced the sensitivity of detection. This problem was solved by using the Xter$\mathrm{ra}^{\circledR}$ RP18 column (Waters, Milford, MA, USA), which is not only more stable at high temperatures than the silica-based C-18 column but also binds the oxysterols less tightly. This column allows the elution of cholesterol and its oxidized derivatives using acetonitrile in less than $15 \mathrm{~min}$, reducing the peak broadening and providing clean spectral data to aid in their identification.

The sterol analyses were performed using an HPLC system (Model 2790 Separation Module; Waters) controlled with Empower ${ }^{\mathrm{TM}}$ Pro Software (Waters). Sterols were detected using a photodiode array detector (Model 996; Waters) equipped with a $4-\mu \mathrm{L}$ cell. The oxysterols were separated in an Xterra RP-18 column $(4.6 \times 250 \mathrm{~mm})$ running a gradient starting at $15 \% 1 \mathrm{mM}$ phosphoric acid in water, $85 \%$ to $100 \%$ acetonitrile at $60^{\circ} \mathrm{C}$ for $15 \mathrm{~min}$, and flowing at 1 $\mathrm{mL} / \mathrm{min}$. The column was flushed with $100 \%$ methanol for $2 \mathrm{~min}$ and re-equilibrated with 15:85 (v/v) $1 \mathrm{mM} \mathrm{H}_{3} \mathrm{PO}_{4}$ water to acetonitrile for $5 \mathrm{~min}$ between injections. The spectra were collected between 190-300 $\mathrm{nm}$.

Cholesterol and authentic oxysterol standards (Steraloids, Newport, RI,
USA) previously reported to be present in oxidized low-density lipoprotein (oxLDL) (4) were separated as described above (Figure 1). Quantification of all of the oxysterols was performed by peak area integration at $200 \mathrm{~nm}$, with the exception of 7-ketocholesterol $(7 \mathrm{kCh})$, which is done at $237 \mathrm{~nm}$. The $7 \mathrm{kCh}$ is well separated from $7 \beta$-hydroxycholesterol $(7 \beta \mathrm{HCh})$, but the sensitivity at $237 \mathrm{~nm}$ is almost 4 times greater than at $200 \mathrm{~nm}$. The separation of $7 \alpha$-hydroxycholesterol $(7 \alpha \mathrm{HCh})$ and $7 \beta \mathrm{HCh}$ is not complete but sufficient enough to allow a reasonably accurate quantification either by peak area or by peak height.

To determine how well this protocol would perform with an actual biological sample, $100 \mu \mathrm{g}$ of human low-density lipoprotein (LDL) were oxidized using $20 \mu \mathrm{M} \mathrm{CuSO}_{4}$ as previously described (5). The LDL was purified from human plasma (Calbiochem, San Diego, CA, USA) and contains approximately $36 \%$ cholesterol by weight. The oxLDL was hydrolyzed by the addition of $60 \% \mathrm{KOH}$

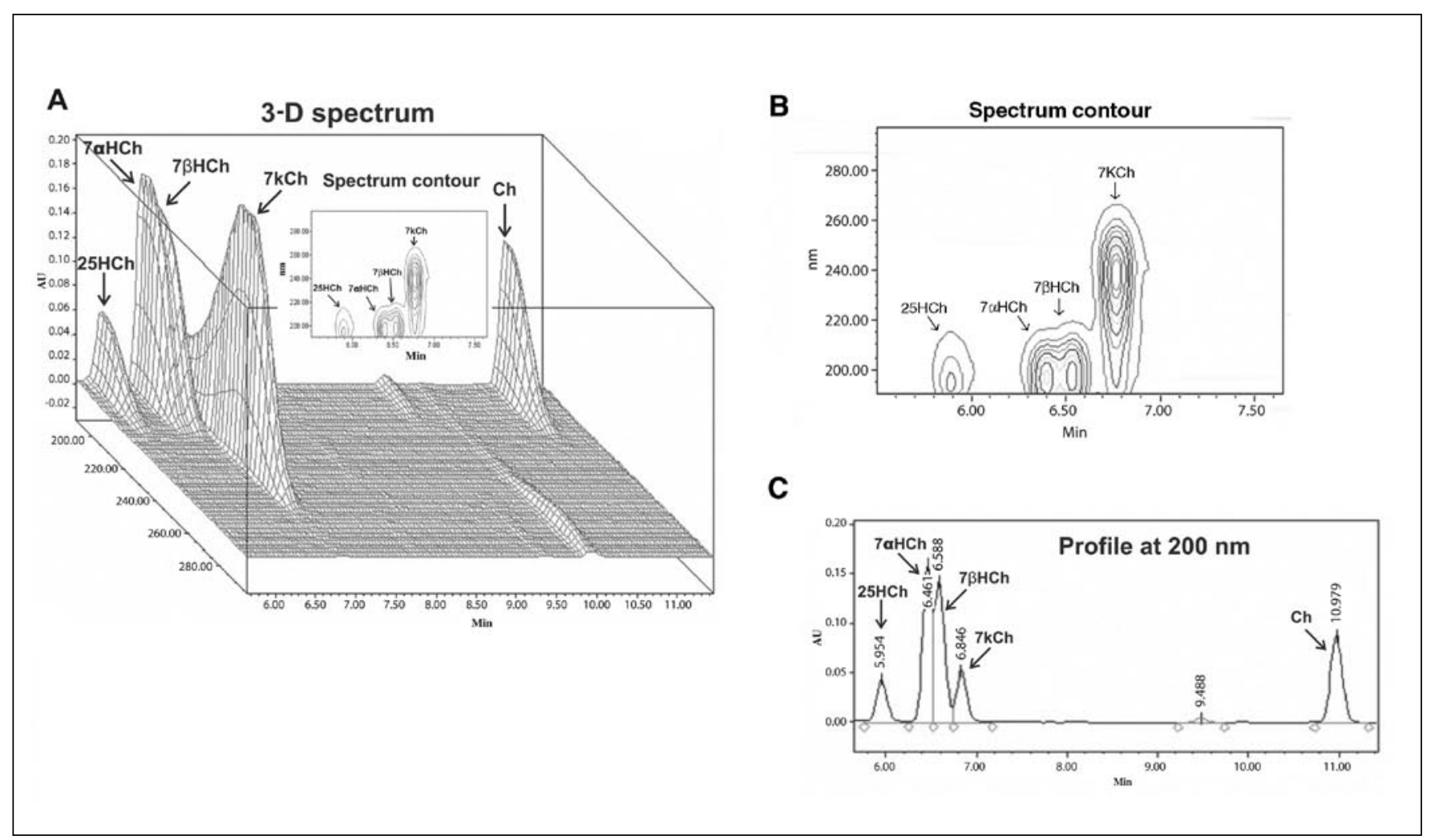

Figure 1. Three-dimensional spectrum of oxysterols commonly found in oxidized low-density lipoprotein. (A) Three-dimensional (3-D) chromatogram showing the separation and spectrum of 25 -hydroxycholesterol $(25 \mathrm{HCh} ; 2.5 \mathrm{nmol}), 7 \alpha$-hydroxycholesterol $(7 \alpha \mathrm{HCh} ; 5 \mathrm{nmol}), 7 \beta$-hydroxycholesterol $(7 \beta \mathrm{HCh}$; $5 \mathrm{nmol}$ ), 7-ketocholesterol (7kCh; $5 \mathrm{nmol}$ ), and cholesterol (Ch; $5 \mathrm{nmol})$. (B) Spectrum contour (enlargement of inset in panel A). (C) Chromatogram at 200-nm wavelength. This is the wavelength used for quantification of all of the sterols except $7 \mathrm{kCh}$, which has a $\lambda_{\max }$ (wavelength at which there is maximum absorbance) at $237 \mathrm{~nm}$. AU, arbitrary units. 
Table 1. Results from the Analysis of Oxidized Low-Density Lipoprotein

\begin{tabular}{|c|c|c|}
\hline \multicolumn{3}{|c|}{$\begin{array}{l}\text { oxLDL } \\
(25 \mu \mathrm{g})\end{array}$} \\
\hline Oxysterol & $\begin{array}{c}\text { Amount } \\
\text { (nmol) }\end{array}$ & Comments \\
\hline $25 \mathrm{HCh}$ & 0.13 & N.A. \\
\hline $7 \alpha \mathrm{HCh}$ & 1.20 & N.A. \\
\hline $7 \beta \mathrm{HCh}$ & 1.23 & N.A. \\
\hline $7 \mathrm{kCh}$ & 1.92 & N.A. \\
\hline $\mathrm{Ch}$ & 4.02 & N.A. \\
\hline $7 \mathrm{k}$-ox-der & $\sim 1.74$ & Based on $7 \mathrm{kCh}^{\mathrm{a}}$ \\
\hline Others & $\sim 1.05$ & Based on $\mathrm{Ch}^{\mathrm{b}}$ \\
\hline \multicolumn{3}{|c|}{$\begin{array}{l}\text { oxLDL } \\
(10 \mu \mathrm{g})\end{array}$} \\
\hline Oxysterol & $\begin{array}{c}\text { Amount } \\
\text { (nmol) }\end{array}$ & Comments \\
\hline $25 \mathrm{HCh}$ & 0.06 & N.A. \\
\hline $7 \alpha \mathrm{HCh}$ & 0.42 & N.A. \\
\hline $7 \beta \mathrm{HCh}$ & 0.42 & N.A. \\
\hline $7 \mathrm{kCh}$ & 0.58 & N.A. \\
\hline $\mathrm{Ch}$ & 1.5 & N.A. \\
\hline $7 \mathrm{k}$-ox-der & $\sim 0.7$ & Based on $7 \mathrm{kCh}^{2}$ \\
\hline Others & $\sim 0.41$ & Based on $\mathrm{Ch}^{\mathrm{b}}$ \\
\hline
\end{tabular}

Oxysterol Amount Comments

\begin{tabular}{lcc}
\hline $25 \mathrm{HCh}$ & 0.009 & N.A. \\
$7 \alpha \mathrm{HCh}$ & 0.082 & N.A. \\
$7 \beta \mathrm{HCh}$ & 0.089 & N.A. \\
$7 \mathrm{kCh}$ & 0.150 & N.A. \\
$\mathrm{Ch}$ & 0.29 & N.A. \\
$7 \mathrm{k}-\mathrm{ox}-$ der & -0.124 & Based on $7 \mathrm{kCh}{ }^{\mathrm{a}}$ \\
Others & -0.057 & Based on $\mathrm{Ch}^{\mathrm{b}}$
\end{tabular}

The quantification of each oxysterol was performed by area integration using the absorption coefficient for genuine standards. The results from the analysis of 10 and $2 \mu \mathrm{g}$ indicate that the limit of the sensitivity under these conditions is approximately $10 \mathrm{pmol}$. The percent recovery based on $\beta$-sitosterol (internal standard) was $75 \%, 83 \%$, and $92 \%$ for 25,10 , and $2 \mu \mathrm{g}$, respectively. oxLDL, oxidized low-density lipoprotein; $25 \mathrm{HCh}, 25$-hydroxycholesterol; $7 \alpha \mathrm{HCh}$, $7 \alpha$-hydroxycholesterol; $7 \beta \mathrm{HCh}, 7 \beta$-hydroxycholesterol; 7kCh, 7-ketocholesterol; Ch, cholesterol; 7k-ox-der, unknown oxidized $7 \mathrm{kCh}$ derivative; N.A., not applicable.

aThe quantification of the unknown oxidized $7 \mathrm{kCh}$ derivative (7k-ox-der) was performed using the area integration at $277 \mathrm{~nm}$ and the absorption coefficient of $7 \mathrm{kCh}$ at $237 \mathrm{~nm}$.

bThe areas for all other unidentified peaks with ultraviolet (UV) profiles similar to cholesterol were added, and the absorption coefficient for cholesterol was used for their quantification. Thus, the quantification of these compounds is inaccurate, and the values are estimates. (w/v) in methanol at $37^{\circ} \mathrm{C}$ for $2 \mathrm{~h}$ in argon gas. The sample was neutralized by the addition of 2 volumes of $50 \%$ acetic acid, and the sterols were extracted with a 50:50 mixture of petroleum ether and dichloromethane. The solvents were evaporated in a stream of argon, and the sterols were dissolved in $100 \%$ ethanol. The analysis of 1/4 of the hydrolyzed sample, equivalent to $25 \mu \mathrm{g}$ of oxLDL, is shown in Figure 2. The plant sterol $\beta$-sitosterol was used as an internal standard because it can be easily separated from cholesterol and its oxidized derivatives.

As previously reported (4), the oxidation of LDL was dominated by the 7-carbon derivatives (Figure 2). The four main sterols found in the oxLDL were $7 \alpha \mathrm{HCh}, 7 \beta \mathrm{HCh}, 7 \mathrm{kCh}$, and cholesterol. Traces of numerous other components including 25-hydroxycholesterol $(25 \mathrm{HCh})$ were also detected. Most of the minor peaks seen at $200 \mathrm{~nm}$ that have UV spectra similar to cholesterol are likely oxidized derivatives. A main peak with a

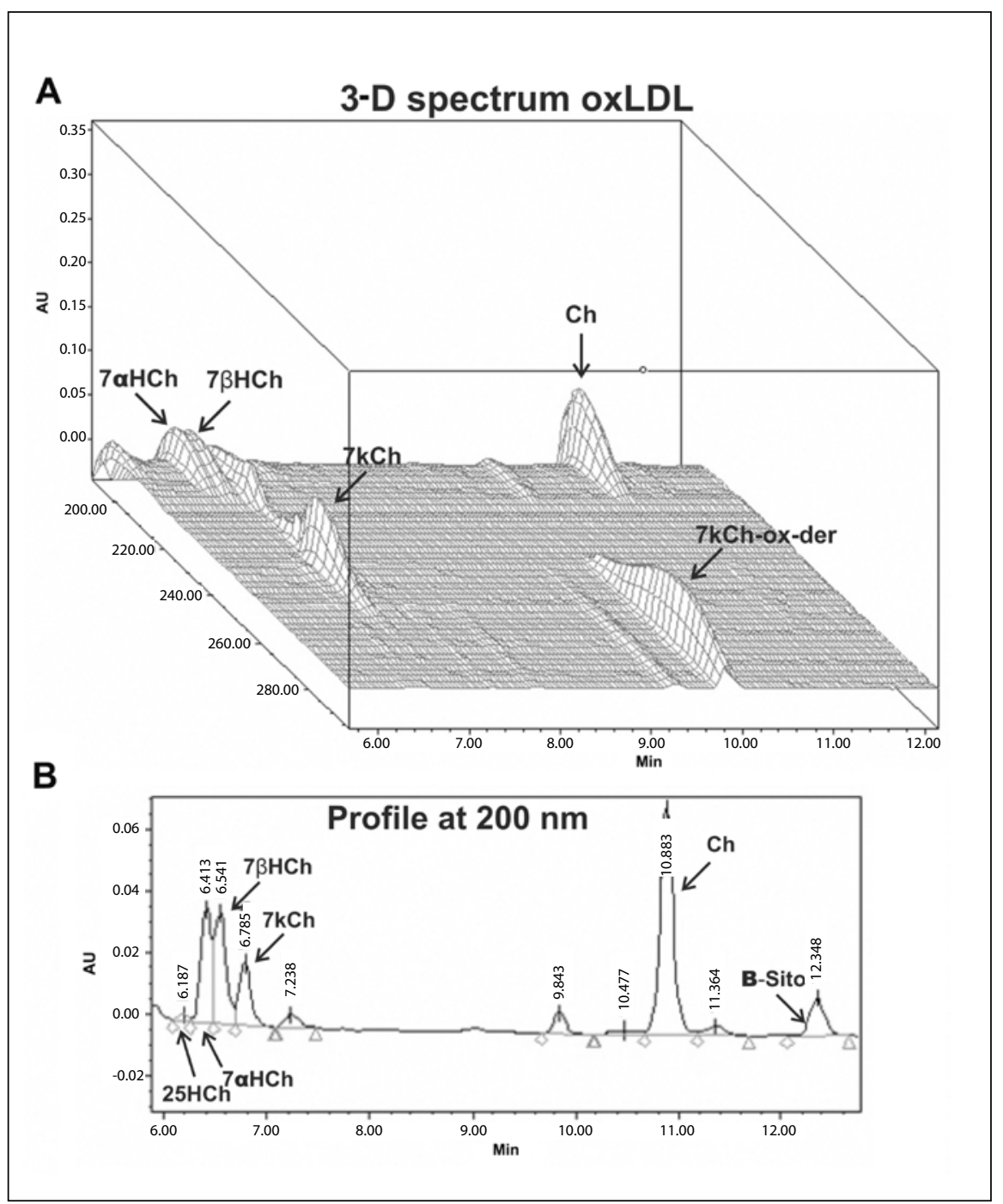

Figure 2. Analysis of human oxidized low-density lipoprotein. The extracted sterols from $100 \mu \mathrm{g}$ [total low-density lipoprotein (LDL)] of hydrolyzed oxidized low-density lipoprotein (oxLDL) were separated as described in the text. (A) A three-dimensional (3-D) chromatogram of the equivalent of $25 \mu \mathrm{g}$ of oxLDL. The main components of the oxLDL are the 7-carbon-oxidized derivatives, but other components were also detected but not identified. A major peak with a $\lambda_{\max }$ (wavelength at which there is maximum absorbance) of $277 \mathrm{~nm}$ is a derivative of 7-ketocholesterol (7kCh) generated during the alkaline hydrolysis. (B) Chromatogram at $200 \mathrm{~nm} .25 \mathrm{HCh}, 25$-hydroxycholesterol; $7 \alpha \mathrm{HCh}, 7 \alpha$-hydroxycholesterol; $7 \beta \mathrm{HCh}$, 7 $\beta$-hydroxycholesterol; $\mathrm{Ch}$, cholesterol; $7 \mathrm{kCh}$-ox-der, unknown oxidized $7 \mathrm{kCh}$ derivative; B-Sito, $\beta$-sitosterol; AU, arbitrary units. 


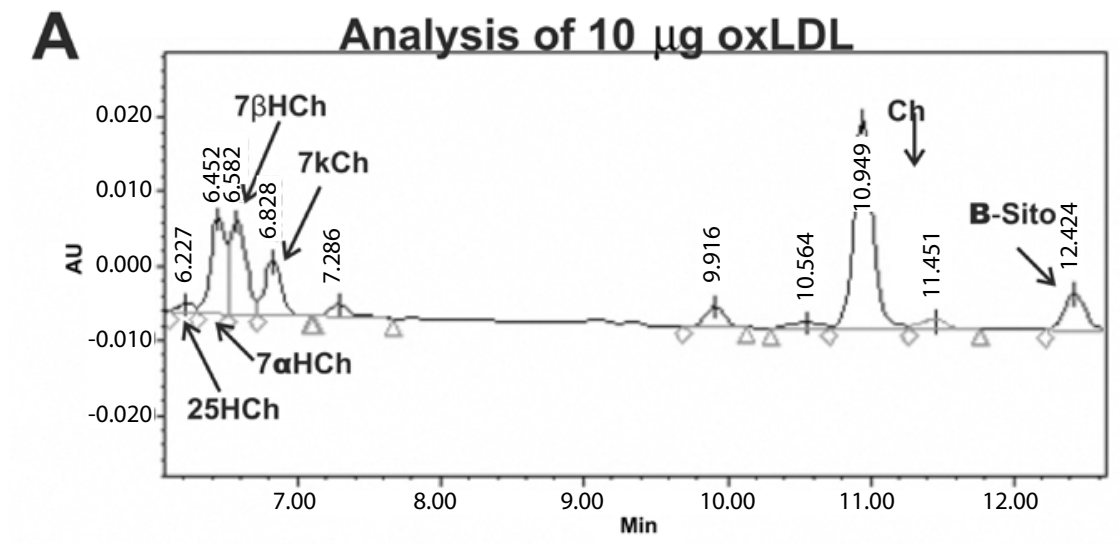

to separate, identify, and quantify most of the oxysterols associated with oxLDL.

\section{REFERENCES}

1.Schroepfer, G.J., Jr. 2000. Oxysterols: modulators of cholesterol metabolisms and other processes. Physiol. Rev. 80:361-554.

2.Brown, A.J. and W. Jessup. Oxysterols and atherosclerosis. 1999. Atherosclerosis 142:128.

3.Shan, H., J. Pang, S. Li, T.B. Chiang, W.K. Wilson, and G.J. Schroepfer, Jr. 2003. Chromatographic behavior of oxygenated derivatives of cholesterol. Steroids 68:221-233.

4.Dzeletovic, S., A. Babiker, E. Lund, and U. Diczfalusy. 1995. Time course of oxysterol formation during in vitro oxidation of low density liporpotein. Chem. Phys. Lipids 78:119-138.

B

Analysis of $2 \mu \mathrm{g}$ oxLDL

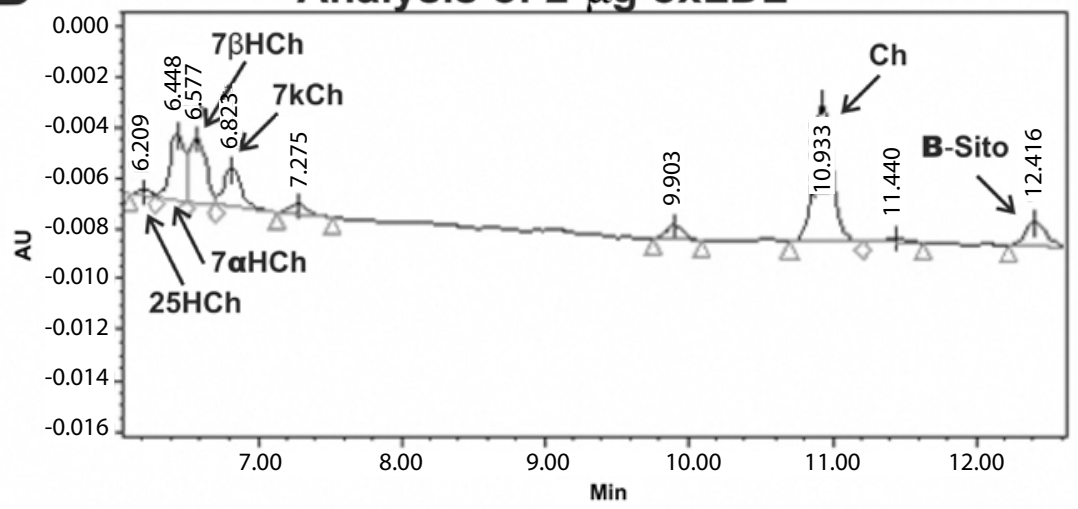

5.Kazuya, M., K. Yamada, T. Hayashi, C. Funaki, M. Naito, K. Asai, and F. Kazuya. 1991 Oxidation of low density lipoprotein by copper and iron in phosphate buffer. Biochem. Biophys. Acta 1084:198-201.

Received 23 January 2004; accepted 11 March 2004.

Address correspondence to Ignacio R. Rodriguez, National Eye Institute, National Institutes of Health, Laboratory of Retinal Cell and Molecular Biology, Section on Mechanisms of Retinal Diseases, 7 Memorial Drive MSC 0706, Bethesda, MD 20892, USA.e-mail: rodriguezi@nei.nih.gov

Figure 3. Analysis of 10 and $2 \mu \mathrm{g}$ of human oxidized low-density lipoprotein. (A) Chromatogram monitored at $200 \mathrm{~nm}$ separating the oxysterols from $10 \mu \mathrm{g}$ of oxidized low-density lipoprotein (oxLDL). (B) Chromatogram at $200 \mathrm{~nm}$ separating the oxysterols from $2 \mu \mathrm{g}$ of oxLDL. The amounts of each oxysterol are shown in Table 1. 25HCh, 25-hydroxycholesterol; $7 \alpha \mathrm{HCh}, 7 \alpha$-hydroxycholesterol; $7 \beta \mathrm{HCh}$, 7 $\beta$-hydroxycholesterol; Ch, cholesterol; B-Sito, $\beta$-sitosterol; AU, arbitrary units.

retention time of $9.844 \min$ and a $\lambda_{\text {max }}$ (wavelength at which there is maximum absorbance) of $277 \mathrm{~nm}$ (Figure 2) was determined to be a derivative of $7 \mathrm{kCh}$, caused by the alkaline hydrolysis. This compound was observed when pure $7 \mathrm{kCh}$ was subjected to the alkaline hydrolysis procedure but not when the other oxysterols were similarly treated (data not shown). The loss of $7 \mathrm{kCh}$ during alkaline hydrolysis has been previously reported (4), but no published information on the formation and identification of this $7 \mathrm{kCh}$ derivative has been found. The identification of this compound by mass spectroscopy is in progress.

The amounts of the oxysterols measured in Figure 2 are shown in Table 1.
The recovery was determined by the measurement of the internal standard $\beta$-sitosterol. The amounts of other oxysterols with spectra similar to cholesterol were quantified using the absorption coefficient of cholesterol.

To determine the maximum sensitivity of the technique, the equivalent of 10 and $2 \mu \mathrm{g}$ of hydrolyzed oxLDL were analyzed. Figure 3 shows the results of the analyses.

The detection limit of the technique (Figure 3) is 10-20 pmol for most oxysterols. The sensitivity may be slightly increased by integrating peaks collected at wavelengths below $200 \mathrm{~nm}$, although this also increases the baseline noise. In summary, this HPLC method provides a fast, simple, and very sensitive technique 